\title{
Romantic relationship experiences and emotion regulation strategies of regular mindfulness meditation practitioners: A qualitative study
}

\section{Itır Erkan MD ${ }^{1}$ (]) | Nilüfer Kafesçioğlu PhD $^{1}$ (1) | Alev Cavdar ${ }^{2}$ (1) | Senem Zeytinoğlu-Saydam ${ }^{1}$}

${ }^{1}$ Department of Psychology, Ozyegin University, İstanbul, Turkey

${ }^{2}$ Department of Psychology, Istanbul Bilgi University, İstanbul, Turkey

\section{Correspondence}

Alev Cavdar, Department of Psychology, Istanbul Bilgi University, Santralistanbul Kazım Karabekir Cad. No: 2/13 34060

Eyüpsultan İstanbul, Turkey.

Email: alev.cavdar@bilgi.edu.tr

\begin{abstract}
Using attachment theory as the framework, this qualitative study focused on the romantic relationship experiences of regular mindfulness meditators and their meditation-naïve or nonregularly meditating partners (NMPs). The sample consisted of eight heterosexual and two same-sex couples. Thematic analysis (TA) yielded seven themes on three levels. Three intrapersonal themes were (a) meta-awareness of one's emotional strategies; (b) shift in emotion regulation strategies; and (c) shift in relationship with oneself. The relationship-level themes of meditators emerged as (d) experiential shift in stressful situations; (e) transformation of the emotional bond; and (f) transformation of the romantic relationship; the nonmeditating partners confirmed the relational and individual shifts due to their partner's practice. Integrating attachment theory with meditation practice can thus be a valuable approach for couple and family therapy. A regular meditation practice of even just one of the partners may be beneficial for the couple relationship.
\end{abstract}

\section{K E Y W O R D S}

attachment theory, couple, long-term meditator, meditation, mindfulness, thematic analysis 


\section{INTRODUCTION}

Mindfulness is described as "the awareness that emerges through paying attention on purpose, in the present moment, and nonjudgmentally to the unfolding of experience moment by moment" (KabatZinn, 1994, p. 4). The positive impact of mindfulness on various physical, mental health, and relational outcomes have been well documented (Cillesen et al., 2019; McGill et al., 2016; Schumer et al., 2018). The studies regarding relational outcomes suggest focusing on the mechanisms by which the relationship benefits from mindfulness and including the partner's perspective (e.g. Kappen et al., 2018). The current study aims at qualitatively describing the perceived effects of long-term mindfulness-based meditation practice on romantic relationships by taking both partners' retrospective views into account. To set the theoretical and empirical background of this aim, the association of mindfulness with the constructs of emotion regulation and attachment will be summarized and studies on the relational outcomes of mindfulness-based interventions will be presented.

\section{Mindfulness, emotion regulation, and attachment security}

Emotion regulation can be described simply as "the processes by which individuals influence which emotions they have, when they have them, and how they experience and express these emotions" (Gross, 1998, p. 275). Defined as an intrapersonal skill, emotion regulation is acquired and manifested in relational contexts. Interpersonal neurobiology (Siegel, 1999) provides an interdisciplinary framework that integrates developmental psychology, attachment theory, systemic theory, mindfulness, and neuroscience to understand how the brain is "literally constructed by interactions with others" (Siegel, 2007, p. 18). It is mainly found on the premise that the infant's brain develops through the relationship with his or her primary caretaker. The brain is physically altered by this early relationship, which in turn affects how the mind operates.

The attunement of the caregiver is a crucial aspect of this early relationship as it is the sole source of emotion regulation for the baby (Stern, 1985). This capacity is internalized later on and provides the basis for the adult attachment and emotion regulation capacities. Siegel (2007) suggested that "with mindfulness seen as a form of intrapersonal attunement, it may be possible to reveal the mechanisms by which we become our own best friend with mindful practice" (p. 16). Supporting this suggestion, Siegel (2007) reported that mindfulness meditation and attachment security have similar impacts on the middle prefrontal cortex, a brain region that serves important functions for both social interactions and self-observation. Mindfulness meditation and securely attached relationships are also involved in the neural integration - the linkage of differentiated elements of a system-between the body and brain areas such as the limbic and cortical regions. This neural integration is claimed to be a result of an attuned relationship. Likewise, mindful awareness as self-attunement may have a similar impact on neural integration. Siegel hypothesized that meditation practice should lead to synaptic strengthening and thickening in the middle prefrontal areas in the brain so that the self-attunement is fostered. This hypothesis is supported by research using magnetic resonance (MR) imaging to detect anatomical changes in the brain in related areas (Engen et al., 2018).

Moreover, hypothetical associations between adult attachment and mindfulness were suggested by Ryan et al. (2007). Securely attached adults are more capable of regulating their emotions without using deactivating or hyperactivating strategies. Similarly, mindfulness also cultivates an open and nonjudgmental awareness of the experience of the self and the others so that the person has no need to distort reality and can, therefore, be more flexibly responsive (Ryan et al., 2007). Shaver et al. (2007) presented another important link by showing the connection between loving-kindness and 
mindfulness and claimed that this is similar to internalizing both sides of a caring and loving attachment relationship.

In sum, it is suggested and supported that mindfulness - as an aspect of emotion regulation capacity - and attachment security emerge from the same background of attuned caregiving and are further subject to change in the interpersonal contexts throughout life. Thus, beyond this shared origin, mindfulness and attachment security might promote each other bidirectionally and have a positive effect on the quality of relationships (Ryan et al., 2007). Within this framework, the impact of mindfulness-based practices and interventions is expected to be observed in the intimate context of adult romantic relationships.

\section{Effects of mindfulness interventions on relationships}

The research and clinical implications of mindfulness have mostly focused on the individual experience, yet there has been growing interest in the last decade in the relational aspects of mindfulness, specifically how it can be implemented into the field of couple and family therapy (Beckerman \& Sarracco, 2011; Gambrel \& Keeling, 2010; Gehart \& McCollum, 2007). Empirical research into the effects of mindfulness on romantic relationships is still in its early stage. However, many studies have investigated the potential benefits of mindfulness meditation and trait mindfulness on romantic relationships.

A meta-analysis of 12 studies by McGill et al. (2016) indicated that the relationship between trait mindfulness and relationship satisfaction was statistically significant with an overall moderate effect size. Gillespie et al. (2015) conducted a qualitative study regarding the relational experiences of partners of Mindfulness Based Stress Reduction (MBSR) graduates after the partner has completed an 8-week MBSRcourse. The study explored the lived experience of 11 couples whose relationship had lasted at least 2 years. The interviewed couples were primarily White and heterosexual; five female and six male partners' experiences were reported. Several intimate partners of MBSR graduates perceived less reactivity, more calmness, and acceptance in their partner. Besides this observation of better emotional balance, it was reported that behavioral shifts were incipient and did not "automatically transfer to improved relationship outcomes" (Gillespie et al., 2015, p. 404). The intimate partners of the MBSR graduates indicated that since the positive impact of the MBSR was just emerging, their partners should continue their practice to be able to observe the relational effects of mindfulness meditation practice.

In Pruitt and McCollum's (2010) qualitative study, seven meditators using Buddhist and Christian practices with at least 10 years of experience were interviewed. The participants were all Caucasian and five were female. The participants conducted various forms of meditation such as Vipassana meditation, centering prayer from Christian practice, and mindfulness meditation. The authors used semi-structured interviews to ask about the personal traits the participants thought they had developed from meditation practice. The results showed that long-term meditators described a deeper awareness of and a disidentification from their thoughts and emotions. They implied acceptance and compassion for the self and the others. The effects of these meditative traits on the participants' relationships were indicated as less reactivity, more freedom and safety for the self and the partner, and a new, deepened experience of connection. The qualitative nature of Pruitt and McCollum's (2010) study provides a very rich context regarding the effects of long-term meditation practice on close relationships, and how the understanding of being in a relationship can be spiritual and self-healing. The lack of a second opinion from the partners and the atypical sample regarding the 10-year meditation practice are limitations of this study. 
As outlined above, there is limited research into the relational effects of long-term meditation practice, and as to the best of the authors' knowledge, none of them takes both partners' views into account. This study, therefore, aims to address these using a qualitative approach.

\section{CURRENT STUDY}

This study relies on the lived experience of mindfulness that comes from regular practice and also on the observations of the other partner. The main research question of this qualitative study is "What is the experience of being in a romantic relationship for the regular meditation practitioner and his or her nonregularly meditating partner?". This leads to several sub-questions: a) Are there any perceived effects of doing regular meditation on the practitioners' emotional, cognitive, and sexual processes; and, if so, what are the reflections of these effects on their romantic relationship, regarding the emotional bond of their adult attachment system in the romantic relationship? b) How do the emotion regulation strategies of the regular meditation practitioner (RMP) reflect on his or her romantic relationship? c) What are the observations of the nonregularly meditating partner (NMP) regarding any positive or negative effects of their partner's regular meditation practice?

\section{METHOD}

\section{Sampling strategy and inclusion criteria}

Criterion sampling was used in this study (Patton, 2002). The criteria included: (a) the meditation practitioner should have been practicing mindfulness meditation for at least 2 years and $2.5 \mathrm{hr}$ weekly. This criterion corresponds to the weekly meditation session of the 8-week MBSR course. Since MBSR is a well-researched course with proven benefits, its meditation durations and styles are taken as the minimum standard. (b) The meditation that mindfulness meditators practice had to be one or more of the following mindfulness meditation styles: focused attention, open awareness, mindful yoga, or loving and kindness meditation based on the mindfulness practices in the MBSR course. (c) The RMP should have been in their current romantic relationship for at least 2 years. (d) The RMP should have started regular practice during the ongoing relationship. (e) The partner of the RMP was not required to be a RMP because the main purpose of the study was to explore the lived experiences of a regularly practicing meditator in a romantic relationship. Although it was permissible for the partners to also practice meditation, they were excluded if they defined themselves as RMPs. With this criterion, the observations of the NMP would not interfere with their own experience coming from their practice and it would be easier for NMPs to differentiate the shift in their relationship coming only from their partner's meditation practice but not both.

\section{Data collection}

After receiving the ethical approval, participants were recruited through yoga studios from major cities in Turkey, and interviews were conducted online via Skype. The interview questions are prepared according to the adult attachment theory framework, focusing on the emotion regulation feature of this theory and the emotional bond between the couple. The interviews were held separately with each participant so that they were not influenced by their partner's responses. Before the interviews, 
an informed consent form and a demographic information form were sent to the participants. The interviews were audiotaped with the consent of the participants. To test the interview questions and to make necessary adjustments, a pilot interview was held with a couple, which met the criteria of this study. After the pilot interview, there was no necessity for changes in the questions. The pilot interview is not included in the data. The questions of the semi-structured interview can be found in Table 1. All interviews were conducted and coded in Turkish. The names of the themes and the participants' quotes were translated into English for this manuscript.

\section{Sampling and participants}

Ten couples participated in this study of which eight were heterosexual and two were female same-sex couples. There were nine female and one male RMPs and seven male and three female NMPs. The average age of the RMPs was 39.7 ranging from 33 years old to 45 years old and the average age for

T A B L E 1 Semi-structured interview guide of regular mindfulness meditator and their partner

Questions for the regularly meditating partner:

How did you start mindfulness meditation?

What is your motivation to continue to meditate regularly?

How did your regular meditation practice affect you?

How did you experience your emotions prior to your regular practice?

How do you experience your emotions now?

How did your current romantic relationship start?

How was your experience in your romantic relationship before you started your regular meditation practice?

How is your general experience in your romantic relationship now?

Has your regular meditation practice affected your partner, if yes how?

How did you express your emotions to your partner prior to your regular mindfulness meditation practice?

How do you express your emotions now?

How does your partner express his or her emotions?

How did your partner express his or her emotions before you started meditating regularly?

How was your sexual life prior to your meditation practice?

How is your sexual life now?

How did you cope with a stressful situation in your romantic relationship before you started to meditate regularly?

How do you cope with a stressful situation in your romantic relationship now?

How did you get support from your partner before you started to meditate regularly?

How do you get support from your partner now?

How does your partner get support from you?

Lastly, would you like to add something?

Questions for the meditation naïve or nonregularly meditating partner:

What are the effects of your partner's regular mediation practice on him/her?

What are the effects of your partner's regular mediation practice on you?

What are the effects of your partner's regular mediation practice on your relationship?

Lastly, would you like to add something? 
the NMPs was 40.9 ranging from 32 years old to 51 years old. Fourteen participants had a bachelor's degree while six had a graduate degree. Eleven of the participants described their economic status as middle class while eight as upper-middle-class and one as low economic class. Ten of the participants indicated no religious belief while four described themselves as Muslims, two as Buddhists, one as an Alevi, one as Agnostic, and one as a Yogi. Twelve participants identified with being Turkish while four did not want to define themselves with a nationality. One defined their nationality as multinational, one as human, one as Eastern European/Turkish, and one as White. The average years of the relationships were 7.85 ranging from 2 years to 14 years. Four couples were married, five were not married but cohabitating, and one was not married and not cohabitating. The average years of meditation for the practicing partner were 2.8 with an average weekly practice of 266 minutes. Six of the NMPs were meditation naïve, while four indicated to have some experience but not a regular practice. The RMPs stated that they regularly practice mindfulness meditation such as body scan, focused attention, open awareness, and loving and kindness meditation.

\section{Data analysis}

This qualitative study used Thematic Analysis (TA; Braun \& Clarke, 2006). TA is a "method for identifying, analyzing, and interpreting patterned meanings or 'themes' in qualitative data" (Braun et al., 2015, p. 95). A six-phase process strategy is used in TA to identify reoccurring patterns throughout the dataset. Phase one involves becoming familiar with the dataset by reading and becoming truly aware of the data. In the first phase, one researcher made the transcriptions and read them recursively to become familiar with the data. The second phase is coding. A code is a brief label to catch the essence of an analytical idea for the researcher (Braun et al., 2015). One researcher generated the codes with adding memos and another researcher reviewed them, and preliminary codes were extracted from the data by these two researchers. Once the coding has reached a satisfactory level for the research question, the third phase started: searching for themes. A theme pinpoints a larger meaning than a code, so many related codes may be clustered under a potential theme. All the codes were summoned into groups, which were the basis for the final themes and subthemes of this study. The same two researchers crosschecked and reviewed their candidate themes and subthemes to examine if they all together represent and describe the whole dataset. Braun and Clarke (2006) described themes as pieces of a puzzle that come together to build an image of the data. The fourth phase is the review. This involves checking the quality of the candidate themes. In this phase, the two researchers checked if the coding has included and highlighted all the important data. The themes were further investigated if they are countable as themes and if they have an important meaning for this dataset. The boundaries and coherence of the themes are also further questioned (Braun \& Clarke, 2006). For the fifth phase, the themes and subthemes were examined by three researchers, to finalize the names and the meaning of these themes. After finalization, one researcher wrote the narrative of the finalized themes and sent them to the RMPs and NMPs for member checking. After the approving responses were taken from the participants, the last phase, writing the report, was conducted.

\section{Trustworthiness criteria}

To improve credibility, the study included both members of the couple as participants. Thus, the perspectives of both partners were obtained to get a more accurate picture of the romantic relationship. Also, member checking was conducted to check whether the extracted data matched the participants' 
experiences after the completion of the TA. Seven regular mindfulness meditators and seven partners responded to the themes with positive feedback. Lastly, to ensure trustworthiness, continual expert checking of themes from the second and the third author was obtained. The second author is an experienced qualitative researcher, couple and family therapist, and supervisor. This study also aimed for transferability by its sensitivity to the diversities among the participants and the inclusion of two same-sex couples.

\section{RESULTS}

The research questions of this study focus on the perceived intra- and interpersonal implications of regular meditation practice. Accordingly, the findings of this study, presented in seven themes, are organized in three levels: (a) intrapersonal-level themes of the regularly meditating partner, to explore the practitioner's emotional, cognitive and sexual processes, and emotion regulation strategies; (b) relationship-level themes of the regularly meditating partner, to discover the experiences of being in a romantic relationship for the RMP and their emotional bond in their adult attachment system; and (c) theme of the nonregularly meditating partner, to describe the observations of the NMP regarding the hypothetical effects of the regular meditation practice of their partners and their general relationship experiences. The actual names of the participants have been changed to pseudonyms to maintain the anonymity of the participants. A visual organization of the themes can be found in Table 2 .

\section{Intrapersonal level: Meta-awareness of one's emotional experiences}

The first theme of meta-awareness of one's emotional experiences denotes the experience of being aware of the working system of the mind and the change in one's way of observing inner states. These experiences surpass the simple awareness of any emotional state and reflect a meta-awareness of the mind and psyche. The RMPs indicated that knowing the impermanency of their emotions helps them to stay with that emotion without the need to control or suppress it.

Typically, this meta-awareness was described as keeping an observing eye on their inner states and witnessing the process. Gamze's (35-year-old woman practicing for 2.5 years):

TA B L E 2 A visual organization of themes

\begin{tabular}{ll} 
Level & Theme \\
\hline Intrapersonal level by RMP & $\begin{array}{c}\text { Meta-awareness of one's emotional } \\
\text { experiences } \\
\text { Shift in emotion regulation } \\
\text { strategies } \\
\text { Shift in relationship with oneself }\end{array}$ \\
\hline Relationship level by RMP & $\begin{array}{l}\text { Experiential shift in stressful } \\
\text { situations }\end{array}$ \\
& $\begin{array}{l}\text { Transformation of emotional bond } \\
\text { Transformation of the romantic } \\
\text { relationship }\end{array}$ \\
\hline Partner level by NMP & $\begin{array}{c}\text { General positive effects of the } \\
\text { meditation practice }\end{array}$
\end{tabular}


“...I start to observe my emotions; where is this emotion? How does it make me feel?.. In

a way you take a step out of that state, observing and staying with that."

Six of 10 RMPs underlined the benefits of being aware that the emotions are transient, when not immediately acted upon, especially when they felt anger, fear, or sadness. Canan (45-year-old woman practicing for 3 years):

"I can choose not to act on something that is not permanent. Before starting regular meditation, I didn't have that kind of awareness. I thought that anger or fear is persistent."

This also illustrates how meditation itself brings an enhanced emotion regulation by teaching the nature of thoughts and emotions. Via the practice of sitting during meditation and observing emotions, the practitioners seem to get used to the nature of their thoughts and emotions.

\section{Intrapersonal level: Shift in the emotion regulation strategies}

All RMPs reported changes in their emotion regulation strategies, forming the second theme of this study. Participants described a "decrease of the intensity of the emotions" and "increased capability of staying with negative emotions."

Five RMPs indicated that they repressed their emotions before regular meditation practice. Five reported generally calmer mood and disidentification from thoughts and emotions during a stressful event, which comes from their practice. They described this as an automatic shift. Selin (44-year-old woman practicing for 6 years):

"I was very moody until college than I suppressed it and I was very depressed until I got married... I suppressed that depressive state after getting married... Then I started to meditate regularly and maybe one and a half year later I was more able to regulate my emotions instead of suppressing them... Now, I experience my emotion as it is. Like I let them be."

Seven RMPs described that their intensity of emotions decreased and shed more light on the basis for this shift in emotion regulation. Ilkim (39-year-old woman practicing for 2 years):

"I used to live my emotions very intensely. Very, very intense. Now it is much less intense. And if an emotion arises and I lose my awareness, I come under the influence of the emotion. But I can escape that influence much more quickly. Sometimes, it can resolve immediately."

Seven of 10 RMPs mentioned increased capabilities of staying with negative emotions. That is, on experiencing a strong emotion like sadness or fear, they are less likely to use strategies such as distraction or repression; instead, they just simply stay with that emotion fully. This capacity came from their meditation practice. As Peri (41-year-old woman practicing for more 2 years) put it:

"I never repress my feelings, but I also do not hold on to them. I can stay with these negative emotions. I don't sublimate them, and I don't ignore them because then I feel under pressure. My emotions are real. They exist. I don't ignore them. I stay with them.” 
The first theme of meta-awareness that allows one to distance himself or herself from the emotions and witness them as they go by is intertwined with this second theme of transformation of emotion regulation strategies.

\section{Intrapersonal level: Shift in relationship with oneself}

The third theme represents participants' accounts of an altered relationship with themselves after doing regular mindfulness meditation. Almost all RMPs claimed that they were more attuned with their own emotions and thoughts, and more aware of their expectations. As an outcome, an increase in one's self-compassion capacities has been mentioned. Aysu (44-year-old woman practicing for 2.5 years):

"I was feeling alone in the past. I didn't have the capacity to be with my self. Meditation made me friends with myself. We get along much better right now..."

Aysu described being better "friends with herself" after her regular meditation practice and how the capacity to look into her thoughts and emotions has been enhanced. Several participants also described similarly to use meditation as a tool to gain contact with themselves.

An increase in the self-compassion was mentioned by six of the 10 RMPs. RMPs reported a sincere curiosity in both their suffering and that of others. Selin (RMP):

"Now meditation has transformed me. I am aware of a glimpse of compassion and what it means. It opens my heart. Also, about loving myself; when I saw myself in the mirror, I didn't like my butt or some other parts of me. That has disappeared. There is love for myself growing inside me. That love is blooming."

In addition to a growing self-compassion, two RMPs stated an increase in self-esteem, and three RMPs mentioned feeling empowered. Overall, a more self-appreciative stance was evident in the accounts of the regular meditators.

\section{Relationship level: Experiential shift in stressful situations}

All the RMPs described how practicing regular meditation had induced differences or new experiences in stressful situations. Each RMP seemed to have developed different methods to handle a stressful argument like staying together or giving pauses. Three RMPs reported that the blaming attitudes during conflict had decreased for both parties, while two RMPs claimed that they now give feedback instead of blaming others. Three RMPs said that they can talk more easily about their fights. Peri (41-year-old woman practicing for more than 2 years) and Esin (37-year-old woman, partner of Peri, NMP) represented a quite striking example of this theme as they were going through a difficult time in their relationship at the time of the interview. Peri learned that her girlfriend had an affair with one of their mutual friends. She described below how she was able to react less negatively to a very overwhelming situation:

"I could have got caught up with these overwhelming feelings and I could have acted on them; maybe I could have even been violent. But I wasn't. I was able to stop myself... 
Being able to stop is so important because those urges are very powerful; they can easily control you. But I didn't let them control me."

Nine of the 10 RMPs mentioned being less negatively reactive toward their partners or someone they are related to. They described this negative reactivity as an automatic response in a stressful situation, especially when angry or fearful. The RMPs claimed to have more control over this automatic behavior. Further, six of 10 participants said that they experienced fewer conflicts in their relationship after starting their meditation practice. While acknowledging that they and their partner still might not agree on something, the experiential shift enabled them to avoid turning disagreements into stressful conflicts.

This interpersonal theme of an experiential shift in how stressful situations are handled is closely related to the intrapersonal themes reported above, especially the enhanced emotion regulation strategies. The RMPs' enhanced ability to remain calm seems to be positively reflected in their automatic behaviors. As Kerem (40-year-old man practicing for 3 years) illustrates it,

\begin{abstract}
"My stress level has decreased a lot. When a stressful emotion arises in me, it can dissolve in seconds... When my wife was stressed out in the past, she was projecting it on to me and I was interfering; 'You shouldn't think like this; you should do this, etc.' ... Now those feelings are transformed into compassion or just noticing that my wife is under stress, and I now approach her with an open and supportive attitude. Now, I think like how can I help her?".
\end{abstract}

Kerem's experiential shift is dramatic because he described attuning to another person's emotions without the interference of his own. In a conflict, where the stress is elevated quickly, to stay in this position of empathy and understanding seem to be very adaptive for their relationship, which is a shift his wife also acknowledged.

\title{
Relationship level: Transformation of the emotional bond
}

This theme was named as "transformation of the emotional bond" because all RMPs described a shift in their way of emotionally bonding or experiencing intimacy with their partners. When describing their bond before meditation, RMPs listed many negative relational experiences and anxieties such as constantly being jealous, experiencing strong anxieties about the course of the relationship, feeling threatened in the relationship, needing to control the partner, experiencing insecurities about the relationship, and not being able to ask for support. After meditation, RMPs experienced a transformation in how they perceive their relationship, particularly in areas of easily asking for support, experiencing less relationship-related anxiety (e.g., jealousy, anxiety about breaking up, etc.), and being able to express emotions more easily and openly.

Kerem described how he learned to look deeper into his feelings and how his expression of love toward his wife had been transformed through the journey of regular meditation practice:

"And my way of showing love to her was different before. It was pretentious. I was thinking like 'Now, I have to show some affection' and I acted on these opinions. Of course, my wife understood this, and she tested me if it was real or not. Right now, I show my love for her when I really feel it and in the way that I feel it." 
Seven RMPs stated that they can more easily and more clearly talk about their emotional states after doing regular meditation. They described themselves as previously being either more inhibited or unable to express them clearly or without anxiety. With this shift, these RMPs also indicated that they were more caring about their partner's feelings. Gamze (35-year-old woman practicing for 2.5 years) reported an enhanced capacity of self-disclosure of her emotions in her relationship after her regular practice and noted how she benefitted from this:

"I couldn't talk about my feelings. They were growing in me, but I couldn't talk about them. I frowned or withdrew into myself or I implied them instead of expressing them straight- forward. Now, I can talk about how I feel much more easily."

Six of 10 RMPs indicated that their regular meditation practice helped them to decrease or eliminate anxieties related to their relationship. These included: being jealous of the partner, anxiety about an imagined break-up, anxiety about separating from the partner, anxiety about partner's opinions of them, anxiety about loneliness, and anxiety about getting into a conflict.

Aysu (RMP):

"I was anxious that he would leave me. He never left but I couldn't see that.... With my meditation practice, I can see my own strength. I am better with myself and I am less afraid of being alone because being alone is not that scary anymore... I can manage my anxieties more inside me. And this way it is not a burden for him. I think that makes it more of a healthy relationship."

\section{Relationship level: Transformation of the romantic relationship}

All RMPs described a transformation of their romantic relationship. This transformation has a broader content regarding the cognitive shift in partners but also an experiential transformation like in their sexual life. They described being more present during sex, enhanced compassion of and acceptance for the partner, and redefining of the boundaries.

They indicated that their relationship was more peaceful after their regular practice; they know their expectations and needs in the relationship better and that they do not take every comment of their partners personally. These participants also claimed to be less resentful toward their partners and less dependent on them. Before practicing meditation, three RMPs said that they had tolerated certain behavior or situations in the relationship. However, meditation made them aware of this tolerance, so that they challenged their partners by not tolerating that behavior or situation anymore. For example, Selin, who were about to get divorced during the interview described:

"I was letting my husband oppress me. For some benefits, of course, I was saying to myself: 'We have a family. He provides for us. We leave an upper-class life. We live well.' And I tricked myself that everything would be all right in the end. But I shouldn't accept his mean and rough behavior towards me. I realized that after a while in my regular meditation practice... I was trying to tolerate his behavior. But deeply I wasn't. Now after my meditation practice I feel empowered in the relationship. And I am also more aware of his hardship, his pain. I understand him much better now... If I didn't do meditation, I wouldn't maybe ask for a divorce, but I would be sick most probably." 
Selin portrayed enhanced compassion toward herself and her husband but that was not defined as an enhancement in their compassionate love since she decided to get divorced after starting her regular meditation practice.

It is also important to notice that four RMPs said that starting their regular practice might have been hard for their partners because of the perceptual and behavioral changes that the RMP went through. Talya (33-year-old woman practicing for 3 years), for example, described beginning meditation practice as "going to not-so-great places" and mentioned how she struggled during this initial phase:

"At the beginning of my meditation practice, I was thinking that I had a better relationship because I was doing what should be doing in the relationship without questioning... With my meditation practice, I was more aware of my existential responsibility. This might have been challenging for my husband."

About their sexual life besides being more present during sex, four participants described that they experienced more pleasure and harmony during sex. They indicated that there is an elevated quality in their sexual bond since the mindful touching of the partner makes the sexual process much more pleasurable. As Mina (43-year-old woman practicing for 2 years) put it:

"I think I didn't know what I was doing when I touched my partner before starting my meditation practice. Now I make love in the present moment with her, when I touch her and kiss her. Sex is not something I think about anymore. I feel it more. I feel him more. Sometimes I just want to breathe with him. Sometimes I ask to go slow. Before my practice, we were doing sex in a hurry, without feeling each other."

Three indicated that they can talk more easily to their partners about their needs, expectations, and the pleasures they experienced. Canan portrayed how her sex life changed and how meditation affected this:

\begin{abstract}
"To focus on the moment is what makes any action beautiful. Like eating or sex. In the past during sex, it was for me like 'What is new? Surprise me!' But now to get aligned with your body and emotions in the present moment and to have sex like that changes the whole sexual act. Having sex without thinking about before or after makes the experience so different. My meditation practice helped me a lot in using my five senses and being in the sexual relationship totally with my body and not with my thoughts. Without thinking of my duties or other stuff and just having sex with my body, being really there with my partner as one body changes the whole sexual experience."
\end{abstract}

Six RMPs described how they were more compassionate and accepting toward their partners after regular meditation practice. They defined this as being able to be more considerate about their partners' suffering or other emotions such as fear or anger. These RMPs indicated that they now understood their partners' situations and their challenging emotions better and were able to prioritize their partner's best interests much more in such situations. Peri (RMP), for example, described how she is much more considerate about her partner's emotional states and how her perspective about her girlfriend has changed with meditation practice:

"With regular meditation practice, a lot of compassion towards my partner was evoked in me. I am much more understanding of her. My capacity for empathy improved. I don't look at my lover just as my lover. I am more aware now that she is a human being with 
many different emotions and that she can be hurt by others. I am more considerate not hurting her."

Six RMPs indicated that they were now more mindful about their boundaries and the partner's in the relationship and how they were able to adjust the relationship dynamics since starting a regular meditation practice. They described this as being individually more aware of their needs and expectations while also becoming better at giving enough space for their partners. These adjustments made their relationship more peaceful and flexible.

Sena (33-year-old woman practicing for 2 years) described how her awareness of her expectations and needs changed her behavior toward her husband and how this shift altered their relationship:

\begin{abstract}
"Before my meditation practice, I was doing some stuff, like rituals, going to the motherin-law's, etc. because it needs to be done. Now, I can say no to the things that I don't want to do. In the past, I was doing these things for the sake of my husband. Now, if I don't want to do it, I don't - and I don't want my husband to be in the same position either."
\end{abstract}

\title{
Nonregularly meditating partner level: General positive effects of the meditation practice
}

This theme of the NMP covers all the positive effects of the regular practice on the RMP and their relationship. Partners observed a more peaceful mood and less reactivity in their partners.

NMPs observed that their partners (RMPs) were calmer, more grounded, and more peaceful. Three NMPs found their partners to be more compassionate and loving, and four said that their partners showed more positive regard in stressful situations and better coping abilities. Seven NMPs found these behavioral shifts as positive influences for the relationship. They implied that their relationship had become more peaceful and less problematic with better resolution of stressful events in the relationship. Four NMPs said that they argue less now, while one NMP suggested that their relationship would have ended before if their partner had not begun meditation practice.

Nihal (42-year-old woman, partner of Canan, NMP) described the effect of her partner's regular meditation practice on their relationship as follows:

"I feel more relaxed now; I can communicate with her more easily and I feel like I am understood. There is a harmony between us. We have fun together."

Four NMPs indicated that their partner's meditation practice made themselves calmer while three felt they had become more open toward their partner and able to ask for support more easily. Four NMPs said that meditation had also attracted their attention although the other four indicated no interest.

Observation of the peaceful mood of the partner reflects the observations that the RMP had become calm, serene, and emotionally balanced. As Akın (35-year-old man, partner of Gamze, NMP) says:

"I think Gamze has psychological well-being and a calm mood now. She has a more positive attitude and she is more understanding. There is a change that happened in her... Because she sees things more clearly, we don't have ridiculous arguments. Parallel to this, our relationship is more peaceful with fewer problems. The tension has dropped nearly to zero." 
Similar to RMP's reporting a transformation in their response to stress, eight NMPs reported less reactivity in their partner's behaviors in stressful situations. They described this shift as "being less caught up with negative emotions" or "not giving instant negative reactions" or "being more grounded and in control in a stressful situation."

As Can (48-year-old man, partner of Mina, NMP) puts it:

\begin{abstract}
"Mina is calmer and sees things more clearly. She can handle conflict or a stressful event much better after her meditation practice... She is much less reactive but in a good way. Not as becoming silent when someone else yells at you. That's not what I meant. She can stay in a negative situation, without herself being negatively reactive."
\end{abstract}

The nonmeditation partner-level theme indicates that both intrapersonal and interpersonal-level positive changes attributed to regular meditation by RMPs were observed, acknowledged, and appreciated by their partners. Four of the NMPs also indicated that they want to start to do meditation in the future and they tried to do meditation with their partners from time to time. They quoted that doing regular meditation is an important lifestyle change, which was not easy for them to implement into their lives yet.

\title{
DISCUSSION
}

The findings of the current study provide insights into the link between regular mindfulness practice and romantic relationship experiences. The main contribution of the study was the identification of both intrapersonal and relationship constructs that from an attachment perspective highlight how regular mindfulness practice may support security in couple relationships, especially through emotion regulation processes. Such constructs found in this study as meta-awareness of emotional experiences, use of effective emotion regulation strategies, self-compassion, constructive management of stressful situations, open emotional expression, and presence, compassion, and acceptance in the relationship are all in line with the gains of regular mindfulness practice and experiences of secure individuals in romantic relationships. These findings are parallel with what has been found in previous studies. For example, in their study with mindfulness practicing couples, Pruitt and McCollum (2010) also found similar themes such as gained awareness, disidentification from thoughts and emotions, and compassion and loving-kindness for the self and others (Pruitt \& McCollum, 2010). Also, similar relational traits such as less reactivity, freedom, and safety for the self and the partner. These parallel findings are important since they refer to the universality of these constructs regarding the link between mindfulness and romantic relationship experiences.

\section{Intrapersonal constructs}

The current study's intrapersonal findings related to the regular meditation practice included metaawareness, a shift in emotion regulation strategies, and a better relationship with oneself. Metacognitive awareness is a feature of cognition whereby one can see one's thoughts and emotions as transient rather than a part of the self. It is also closely related to meta-cognitive insight defined as "the way mental phenomena are experienced as they arise" (Teasdale et al., 2002, p. 286). The RMPs in this study similarly described a meta-awareness of their thoughts and emotions with an insight into their impermanent nature. Safran and Segal (1990, p. 117) described the "impermanence of the emotions" in the context of "decentering", "a process through which one can step outside of one's 
immediate experience, which fosters a recognition that the reality of the moment is not absolute, immutable, or unalterable, but rather something that is being constructed." They stressed that it is a potential mechanism for change in psychotherapy, whereas the inability to decenter makes people vulnerable to psychological and social maladaptation.

The findings of the current study concerning the shifts in emotion regulation strategies relate to the decrease in the intensity of emotions and staying with negative emotions. Ryan et al. (2007) suggested that nonjudgmental awareness of oneself and the other helps partners to distort reality less and thereby reduce the deactivation or hyperactivation emotion regulation strategies. Deactivation and hyperactivation strategies are identified as ineffective emotion regulation strategies when used by individuals with insecure attachment strategies (Mikulincer \& Shaver, 2016). While avoidant attachment strategies include hindering or inhibiting emotions to deactivate attachment-related needs, anxious attachment strategies include the overstatement of the degree of threats and exaggeration of vulnerability and helplessness (Mikulincer \& Shaver, 2019). Mindfulness encourages superior regulatory outcomes than such expressive suppression, rumination, or distraction (Farb et al., 2014). Especially, the theme of "staying with negative emotions" described the "nonjudgmental exploration of emotional states" and it is also a unique feature of mindful emotion regulation as described above. The RMPs of the present study described their emotion regulation strategies not as diverting themselves from negative thoughts and emotions but as simply staying with them. This finding can be explained by the regulatory strategies in mindfulness practice, which promote exploration of introspective states without considering whether they are perceived as negative or positive (Farb et al., 2014).

Another intrapersonal theme found in this study pointing to the "shift in the relationship with oneself" can be associated with enhanced self-attunement (Siegel, 2007). Similar to Siegel's description of self-attunement gained in mindfulness practice as being friends with oneself, the participants of the current study described a deeper and richer relationship with themselves and mindfulness practice as a way of connecting with that "friend." From an attachment perspective, attachment security has been described as the basis for kindness to both self and others (Shaver et al., 2017). Attachment security comes from both having a supportive and responsive family of origin and adaptive romantic relationships with the cultivation of a positive framework toward the self and others. Insecure attachment styles, however, hinder self-acceptance and self-approval.

\section{Relational constructs}

At the relational level, the RMPs of the current study indicated a shift in how they interact with others during stressful times. More specifically, they reported less negative reactivity and fewer conflicts. Less reactive expressions are important for the quality of romantic relationships. For example, Wachs and Cordova (2007) found that the regulation of anger expression fully mediated the relation between dispositional mindfulness and marital quality. Negative reactivity is also associated with attachment security. In a quantitative study, Wei et al. (2005) found that attachment anxiety and avoidance strategies are associated with negative mood and relational problems such as negative reactivity or emotional cut-off. Negative reactivity mediated the association between attachment anxiety and relationship problems. This finding is important to understand the link between the "less negative reactivity" and the attachment security system.

At the relational level, participants also expressed a transformation in their emotional bond. Disclosing their emotions to their partners and decreased anxiety about the relationship represent the main dynamics behind this transformation. They are closely related to the attachment system and its avoidant and anxious attachment regulation strategies. According to Hazal and Shaver (1987), the 
regulatory strategies of avoidant adults are associated with fear of intimacy, ambivalent emotions, and jealousy. In contrast, anxious adults obsessed about the relationship experienced a strong need for reciprocation and closeness, ambivalent emotions, and extreme sexual attraction and jealousy. Firstly, "self-disclosure of emotions" gained through regular mindfulness practice described by the participants of the current study signify that they did not use these avoidant attachment strategies even though they mentioned emotional withdrawal before their meditation practice. Secondly, reports of decreased anxiety about the relationship may be linked with less use of hyperactivation strategies that are generally found in anxiously attached individuals.

The last relationship theme is related to the transformation of the romantic relationship. This theme was portrayed as being more compassionate and accepting of the partner. Shaver et al. (2007) linked attachment theory and self-compassion as internalizing both sides of the attachment relationship as caring for and loving oneself while caring for and loving the others. Secure attachment is associated with compassionate caregiving capacity (Gillath et al., 2005). Compassion is also important in Buddhist Philosophy. Mindfulness as the core of Buddhism acts as a framework for the meditation practitioners, an outlook for themselves and for others, which has a crucial impact on the meditators.

In their sexual life, RMPs indicated to be more present during sex, which led to a deeper experience with enhanced sensual awareness. Clinical research focused recently on mindfulness-based therapies and interventions as a treatment for sexual disorders showing promising results (Jaderek \& LewStarowicz, 2019). Also, the findings of this study underline a trajectory in the improvement of sexual relationships and physical intimacy. With regular meditation practice, the present moment awareness of the RMPs seems to be positively impacting the physical intimacy in their romantic relationships.

Another relationship-level theme was re-defining of the boundaries in the relationship. RMPs expressed differentiating themselves from their partners while also respecting their own boundaries. They described this as a new way of relating with each other. Because of the structure of this study, the themes reported by the NMPs of the current study should be considered as partner checking for synchronicity agreement between the lived (RMP) and observed (NMP) shifts in the romantic relationship The NMP's observation of the calmer mood of RMP reflects the enhanced emotion regulation reported by all RMPs. The NMPs observing less reactivity in their partner also reflects the NMPs' perspectives on less negative reactivity.

There is very limited literature on the experiences of romantic partners of mindfulness meditators. Gillespie et al. (2015) reported that the intimate partners of the MBSR graduates saw the positive effects and they indicated an improved emotional balance and less negative reactivity but only emerging. These are almost identical to the themes of this study. However, the NMPs in this study described the positive effects not as emerging but as favorable traits that benefitted both and the romantic relationship positively, including easier conflicts resolution. In the present study, in which the RMPs are more experienced and regularly practice meditation, most NMPs reported a behavioral shift in the RMP that benefitted themselves, their relationship, or both.

\section{CLINICAL IMPLICATIONS}

The findings show that NMPs can notice the effects of RMP's practice. Thus, it may not be necessary for both partners to practice mindfulness meditation for each to benefit from the relational effects of meditation practice. This suggests that mindfulness-based courses focusing on romantic relationships, for individuals and/or couples, could be a useful tool in couple and family therapy (CFT). This is important, because the motivation for doing meditation of each partner may be different. MindfulnessBased Relationship Enhancement (Carson et al., 2004), for example, is designed for couples with 
low- to medium-level distressed relationships. However, mindfulness-based relationship course structures enable also individuals to attend, and may be useful for the romantic relationship.

Since the findings of this study are based on the reports from RMPs and their partners, it can be useful also for the partners to help each other to meditate regularly. An idea could be that a "contract of support" between the partners could be discussed and agreed on in a therapy session, with which the couple can give space to each other for meditating regularly. The meditating hours, schedules, and other duties could be shared. For example, this "contract" could include for the meditating partner an arrangement for the kids or other duties.

Another idea could be fostering a space for the couples to meditate regularly. This can be a quiet room in the office of the therapist where the couple or one partner can meditate before the session. Since most of the couple therapy sessions are held weekly, the partners may get used to the regularity of the meditation, and the meditation sessions before the therapy sessions would be also useful for the couple to be more in the here and now and emotionally regulated during the session.

Another implication would be to embrace the benefits of regular practice, especially through an attachment security framework. An individual's attachment strategies are mostly automatic processes that remain implicit unless the light of awareness is shed on them. Regular meditation practice greatly assists individuals to become aware of these implicit processes. Moreover, the mindful emotion regulation fostered by meditation practice may help individuals to regulate their attachment-related anxieties. A couple therapy modality with an attachment framework, such as emotionally focused therapy (Johnson, 1996), could strongly benefit from the meditation practice of one or both partners. Although some researchers (Beckerman \& Sarracco, 2011) have already suggested combining these two frameworks, to encourage the clients to start a regular mindfulness practice, it could be also an important assistant in the course of couple therapy. Many aspects of mindfulness are in line with the premises of secure attachment such as acceptance and nonjudgmental regard. The CFT field would expand its horizon with an integrative approach of adult secure attachment and mindfulness.

\section{LIMITATIONS}

Because of the qualitative nature of this study, the sample is nonrepresentative. Since it is rare to find very long-term meditators in Western culture, the sample criterion for the RMP of 2 years of mindfulness meditation practice was specific but not atypical. Another limitation is that the interviews were conducted at one point in time rather than before and after starting a regular meditation practice. To offset this, another sample criterion was that the existing romantic relationship should have lasted longer than the RMP's regular practice. This enabled both partners to at least retrospectively assess any differences in their relationship before and after the RMP began meditation. Another limitation was that the interviewer and coder was the same researcher. To minimize this, there were both expert and member checking of the themes. Also, relationship satisfaction and attachment styles were not measured in this study which could have contributed to the findings.

\section{FUTURE RESEARCH}

Future research on the association between mindfulness and romantic relationship association could include a deeper analysis of the meditation-naive partners of meditators, especially focusing on differences in their down- or up-regulating strategies and their emotion regulation strategies in general. Also, with both partners, the unique emotion regulation feature of the mindfulness and the attachment 
relationship could be researched in greater depth, for example, to determine which specific enhanced mindful emotion regulation strategies have a stronger effect on relationship security.

Comparison of the effects of mindfulness meditation on securely attached couples versus more distressed couples would usefully contribute to the adult attachment and mindfulness literature. Research into CFT would also benefit from studies into how mindfulness mediates the effects on the romantic relationship of specific stressors such as the birth of a child, the loss of a child, the revelation of an affair, or divorce.

Several dynamics were revealed by this study regarding the perceived relational shifts for both partners. Compassion and differentiation of the self were two other trajectories for a possible theory of change in romantic relationships. These traits encouraged by meditation practice and the relationship with attachment security are both fruitful areas for future research into romantic relationships and mindfulness. A longitudinal follow-up of the partners, when one party continues regular meditation, is also necessary to explore the milestones of this relational shift.

\section{ORCID}

Itır Erkan (D) https://orcid.org/0000-0002-2324-9226

Nilüfer Kafesçioğlu (D) https://orcid.org/0000-0001-7683-240X

Alev Cavdar (1D) https://orcid.org/0000-0002-2899-4727

Senem Zeytinoğlu-Saydam (D) https://orcid.org/0000-0003-1279-2271

\section{REFERENCES}

Beckerman, N. L., \& Sarracco, M. (2011). Enhancing emotionally focused couple therapy through the practice of mindfulness: A case analysis. Journal of Family Psychotherapy, 22, 1-15. https://doi.org/10.1080/08975 353.2011.551082

Braun, V., \& Clarke, V. (2006). Using thematic analysis in psychology. Qualitative Research in Psychology, 3(2), 77-101. https://doi.org/10.1191/1478088706qp063oa

Braun, V., Clarke, V., \& Terry, G. (2015). Thematic analysis. In P. Rohleder \& A. Lyons (Eds.), Qualitative research in clinical and health psychology (pp. 95-113). Palgrave Macmillan.

Carson, J. W., Carson, K. M., Gil, K. M., \& Baucom, D. H. (2004). Mindfulness-based relationship enhancement. Behavior Therapy, 35, 471-494. https://doi.org/10.1016/S0005-7894(04)80028-5

Cillessen, L., Johannsen, M., Speckens, A. E. M., \& Zachariae, R. (2019). Mindfulness-based interventions for psychological and physical health outcomes in cancer patients and survivors: A systematic review and meta-analysis of randomized controlled trials. Psycho-Oncology, 28, 2257-2269. https://doi.org/10.1002/pon.5214

Engen, H. G., Bernhardt, B. C., Skottnik, L., Ricard, M., \& Singer, T. (2018). Structural changes in socio-affective networks: Multi-modal MRI findings in long-term meditation practitioners. Neuropsychologia, 116, 26-33. https:// doi.org/10.1016/j.neuropsychologia.2017.08.024

Farb, N. A. S., Anderson, A. K., Irving, J. A., \& Segal, Z. V. (2014). Mindfulness interventions and emotion regulation. In J. J. Gross (Ed.), Handbook of emotion regulation (2nd edn, pp. 548-567). Guilford Press.

Gambrel, L. E., \& Keeling, M. L. (2010). Relational aspects of mindfulness: Implications for the practice of marriage and family therapy. Contemporary Family Therapy, 32, 412-426. https://doi.org/10.1007/s10591-010-9129-z

Gehart, D. R., \& McCollum, E. E. (2007). Engaging suffering: Towards a mindful re-visioning of family therapy practice. Journal of Marital and Family Therapy, 33, 214-226. https://doi.org/10.1111/j.1752-0606.2007.00017.x

Gillath, O., Shaver, P., \& Mikulincer, M. (2005). An attachment-theoretical approach to compassion and altruism. In P. Gilbert (Ed.), Compassion: Conceptualisations, research and use in psychotherapy (pp. 121-147). Routledge.

Gillespie, B., Davey, M. P., \& Flemke, K. (2015). Intimate partners' perspectives on the relational effects of mindfulness-based stress reduction training: A qualitative research study. Contemporary Family Therapy, 37(4), 396-407. https://doi.org/10.1007/s10591-015-9350-x

Gross, J. (1998). The emerging field of emotion regulation. Review of General Psychology, 2(3), 271-299. https://doi. org/10.1037/1089-2680.2.3.271 
Hazan, C., \& Shaver, P. (1987). Romantic love conceptualized as an attachment process. Journal of Personality and Social Psychology, 52(3), 511-524. https://doi.org/10.1037/0022-3514.52.3.511

Jaderek, I., \& Lew-Starowicz, M. (2019). A systematic review on mindfulness meditation-based interventions for sexual dysfunctions. The Journal of Sexual Medicine, 16(10), 1581-1596. https://doi.org/10.1016/j.jsxm.2019.07.019

Johnson, S. (1996). The practice of emotionally focused couple therapy: Creating connection. Taylor and Francis.

Kabat-Zinn, J. (1994). Wherever you go, there you are: Mindfulness meditation in everyday life. Hyperion.

Kappen, G., Karremans, J. C., Burk, W. J., \& Buyukcan-Tetik, A. (2018). On the association between mindfulness and romantic relationship satisfaction: The role of partner acceptance. Mindfulness, 9, 1543-1556. https://doi. org/10.1007/s12671-018-0902-7

McGill, J., Adler-Baeder, F., \& Rodriguez, P. (2016). Mindfully in love: a meta-analysis of the association between mindfulness and relationship satisfaction. Journal of Human Sciences and Extension, 4(1), 89-101. Corpus ID: 56346378.

Mikulincer, M., \& Shaver, P. R. (2016). Attachment in adulthood: Structure, dynamics, and change (2nd edn). Guilford Press.

Mikulincer, M., \& Shaver, P. R. (2019). Attachment orientations and emotion regulation. Current Opinion in Psychology, 25, 6-10. https://doi.org/10.1016/j.copsyc.2018.02.006

Patton, M. Q. (2002). Qualitative Research And Evaluation Methods. Sage.

Pruitt, I. T., \& McCollum, E. E. (2010). Voices of experienced meditators: The impact of meditation practice on intimate relationships. Contemporary Family Therapy, 32, 135-154. https://doi.org/10.1007/s10591-009-9112-8

Ryan, R. M., Brown, K. W., \& Creswell, J. D. (2007). How integrative is attachment theory? Unpacking the meaning and significance of felt security. Psychological Inquiry, 18(3), 177-182. https://doi.org/10.1080/10478400701512778

Safran, J. D., \& Segal, Z. V. (1990). Interpersonal Process In Cognitive Therapy. Basic Books.

Schumer, M. C., Lindsay, E. K., \& Creswell, J. D. (2018). Brief mindfulness training for negative affectivity: A systematic review and meta-analysis. Journal of Consulting and Clinical Psychology, 86(7), 569-583. https://doi. org/10.1037/ccp0000324

Shaver, P. R., Lavy, S., Saron, C. D., \& Mikulincer, M. (2007). Social foundations of the capacity for mindfulness: an attachment perspective. Psychological Inquiry, 18(4), 264-271. https://doi.org/10.1080/10478400701598389

Shaver, P. R., Mikulincer, M., Sahdra, B. K., \& Gross, J. T. (2017). Attachment security as a foundation for kindness toward self and others. In K. W. Brown \& M. R. Leary (Eds.), Oxford library of psychology. The Oxford handbook of hypo-egoic phenomena (pp. 223-242). Oxford University Press.

Siegel, D. J. (1999). The developing mind: How relationships and the brain interact to shape who we are. Guilford. Siegel, D. J. (2007). The mindful brain: Reflection and attunement in the cultivation of well-being. W.W. Norton.

Stern, D. N. (1985). The interpersonal world of the infant. Basic Books.

Teasdale, J. D., Moore, R. G., Hayhurst, H., Pope, M., Williams, S., \& Segal, Z. V. (2002). Metacognitive awareness and prevention of relapse in depression: Empirical evidence. Journal of Consulting and Clinical Psychology, 70(2), 275-287. https://doi.org/10.1037/0022-006x.70.2.275

Wachs, K., \& Cordova, J. V. (2007). Mindful relating: Exploring mindfulness and emotion repertoires in intimate relationships. Journal of Marital and Family Therapy, 33, 464-481. https://doi.org/10.1111/j.1752-0606.2007.00032.x

Wei, M., Vogel, D. L., Ku, T. Y., \& Zakalik, R. A. (2005). Adult attachment, affect regulation, negative mood, and interpersonal problems: The mediating roles of emotional reactivity and emotional cutoff. Journal of Counseling Psychology, 52(1), 14-24. https://doi.org/10.1037/0022-0167.52.1.14

How to cite this article: Erkan I, Kafesçioğlu N, Cavdar A, Zeytinoğlu-Saydam S. Romantic relationship experiences and emotion regulation strategies of regular mindfulness meditation practitioners: A qualitative study. J Marital Fam Ther. 2021;47:629-647. https://doi.org/10.1111/ jmft.12462 